maps, in which breeding localities are indicated by arrows. Co-ordination between the two books though not quite faultless is generally very good.

It is to be regretted that the identical section in each book headed 'preserving and shipping specimens', does not make clear that many seabirds 'stranded' on ships or on the land in storms or dark nights are in fact uninjured and can be satisfactorily recorded, identified with the aid of modern photographic equipment and released without ending up in a museum drawer. The collection of specimens should be the exception and not the rule and generally confined to dead birds or those injured beyond recovery. But this is a minor blemish in a pair of extremely serviceable books, which are a model of what such books should be.

HUGH F. I. ELLIOTT

\title{
Night Watchmen of Bush and Plain by David Fleay. Jacaranda Press, Brisbane, $\$ 5.50$. \\ Birds of Australia by Stanley Breeden and Peter Slater. Angus \& Robertson, 55s.
}

As a former Curator of the Melbourne Zoo and Director of the Healesville Wildlife Sanctuary outside Melbourne, David Fleay is well qualified to write about Australian birds and mammals. The first section of this book on 'owls and owl-like birds' records 40 years' devotion to the powerful owl, Ninox strenua, from the day when a schoolboy was attracted to a mysterious call in the forest, through the struggles and heartbreaks of trying to rear them in captivity, culminating in successful breeding only after the book had gone to press. The chatty style and some irrelevant reminiscing in this section may not appeal to all readers but cannot detract from the wealth of information on many aspects of the bird's biology. The breeding is annotated from the pairing of birds in the wild, to the fledging of young in captivity, with details of the various calls, the diet, the changes of plumage and the ailments to which powerful owls are susceptible. The second part is a more impersonal account of the other Australian owls - the frogmouth, owlet-nightjar and nightjars - based again on experience of the birds in the wild and in captivity.

The whole is most admirably illustrated by 12 pages of colour photographs and over 80 in black-and-white, many being close-up portraits of the various species in different stages of plumage. The interest of readers would be stimulated if cross-references were supplied between the photographs and the text, and the value of the book for reference would be enhanced if the plates were indexed: but these are minor criticisms of an excellent book.

The second book introduces Australian birds first by showing their place in the world context; next by chapters on courtship and nesting, raising the young, and feeding; finally in groups by habits and habitats - in rivers and lakes, at night, in rainforests, in the inland, in eucalypt forest, and on ocean and shore. The chapters are profusely illustrated by photographs, including 16 pages in colour, and by Peter Slater's black-and-white drawings, in all depicting over 200 species. The photographs are drawn from the author's own collections and from those of 30 of the leading wildlife photographers in the country, so the quality is excellent and they are particularly exciting in depicting some of the rarer as well as the more familiar birds.

The text suffers from being fitted into the pages where space can be found, but it is unpretentious and informative. The captions to the photographs are perhaps the least successful part of the book, with a tendency to over-generalise, and they are not always easy to correlate with the right pictures. Some clarity seems to have been sacrificed to produce the aesthetically pleasing result. In compensation there is a good index to the illustrations.

B. P. HALL 